\title{
O DIÁLOGO ENTRE DIREITO E MORAL EM ALEXY E POSNER - COMO FICAM AS CONSTRIBUIÇÕES JURÍDICAS PARA AS NANOTECNOLOGIAS?
}

\author{
DIALOGUE BETWEEN LAW AND MORALITY IN ALEXY AND POSNER - HOW \\ ARE THE LEGAL CONSTRIBUTIONS FOR NANOTECHNOLOGIES?
}

\author{
${ }^{1}$ Daniela Pellin \\ ${ }^{2}$ Wilson Engelmann
}

\section{RESUMO}

Os efeitos da Guerra Fria, globalização e tecnologia afetam questões culturais, políticas e econômicas dos países. O conceito de moral foi alterado de lugar. Por detrás do Direito está a moral econômica. As nanotecnologias deverão ser enfrentadas sob esse viés. Pode a Análise Econômica do Direito ser aplicada? É com as teorias de Alexy e Posner e a transposição da moral histórica para a econômica, que a AED se confirma como hipótese a juridicizar as nanotecnologias Para a realização da empreitada será utilizado o método sistêmicoconstrutivista e a técnica de pesquisa será a coleta de dados e revisão bibliográfica interdisciplinar.

Palavras-chaves: Direito. Moral. Análise Econômica do Direito. Nanotecnologias.

\begin{abstract}
The effects of the Cold War, globalization and technology affect cultural, political and economic countries. The concept of morality has changed place. Behind the law is the economic morality. Nanotechnologies will be addressed under this bias. Can the Law and Economics be applied? It is with the theories of Alexy and Posner and the transposition of the historical moral to economic, that this analyse is confirmed as hypothesis for nanotechnologies. For the realization of the research it will be used the systemic-constructivist method and the technique will be data collection and interdisciplinary literature review.
\end{abstract}

Keywords: Right. Moral. Law and Economics. Nanotechnologies.

\footnotetext{
${ }^{1}$ Doutoranda em Direito pela Universidade do Vale do Rio dos Sinos (UNISINOS), São Leopoldo, Rio Grande do Sul, Brasil. Email: daniela.pellin@terra.com.br

${ }^{2}$ Doutor em Direito pela Universidade do Vale do Rio dos Sinos (UNISINOS), São Leopoldo, Rio Grande do Sul, Brasil. Professor e Coordenador Executivo do Mestrado Profissional em Direito da Empresa e dos Negócios pela (UNISINOS). Universidade do Vale do Rio dos Sinos (UNISINOS), São Leopoldo, Rio Grande do Sul, Brasil. Email: wengelmann@unisinos.br
} 


\section{INTRODUÇÃO}

Uma avaliação mais detida, sendo essa a proposta das reflexões desse ensaio, é possível identificar que a moral humana sempre foi o ponto de partida, ou de saída, do homem, dos dilemas da vida, da morte e da sobrevivência: bem e mal; bom e ruim; justo e injusto; certo e errado; belo e feio; santo e profano; aprovável e reprovável; salutar e nefasto; ganhar e perder; matar e morrer. A moral é intrínseca, inerente ao homem; é sua parte integrante; é parte do seu todo completo: corpo, alma e espírito. Tudo o que o homem exterioriza, sozinho ou em sociedade, passa pela sua alma.

É nela que vemos seus elementos bem presentes: vontade, emoções e razão. Não é parte integrante do espírito, onde tem a chama da vida e a imagem do Criador; lugar onde acontece a fusão do Ser com o Ente, tornando-o completo e pleno, um ser excelente; lugar onde a existência toma sentido. É o pensar ético.

ZANNI, do Departamento de Filosofia da Universidade Iberoamericana do México, ao tratar a necessidade de o homem recobrar seu Ser explicou que lo ético no es ya pura constructividad humana para arreglar el lugar del hombre em el mundo, sino es movimento del hombre que se 'da' al ser em correspondência al movimento del ser que se 'da' al hombre. (2001: 406)

O homem é capaz de sobreviver sendo corpo e alma, muito embora, o vazio do espírito o conduza à bancarrota existencial e à falta de sentido; o conduz à irracionalidade; fica desorientado. Trata-se de uma questão de escolha. Ao homem foi concedida a chance da escolha: ser pleno ou não. É onde reside o livre-arbítrio existencial; onde se aloja a responsabilidade individual com a dádiva recebida de viver; como viver e os resultados desse viver.

A alma e o espírito, juntos, em perfeita harmonia, conformam a natureza humana projetada pelo Criador, capacitam o homem a agir e a pensar conforme a expressão do seu Criador. O Ente é a referência, a bússola, o endereço de partida e de retorno; a margem de segurança; a razão de decidir. A razão é o portal de sua vinculação ou de sua separação. Por ela se achega ou se distancia do Ente.

Nesse sentido, os dados atuais mostram que os resultados promovidos pelo homem no percurso de sua existência, escolheu Ser. Esse Ser se realiza pelo excesso da técnica e a projeta, insaciavelmente, em todos os campos dos saberes racionais, a denotar que, por esses frutos, a irracionalidade acometeu toda a alma do homem e, consequentemente, toda a completude de sua conformação moral. 
O recém relatório do Instituto de Pesquisas Econômicas Avançadas (IPEA: 2015), no intuito de auxiliar os avanços nacionais, apresentou documento intitulado: Megatendências Mundiais 2030: o que entidades e personalidades internacionais pensam sobre o futuro do mundo?

A investigação sobre as perspectivas futuras envolveu áreas de população e sociedade; geopolítica; ciência e tecnologia, economia e meio ambiente.

O conteúdo estratégico do documento aponta, como norte geral, no sentido de que o futuro será marcado pelas incertezas. (IPEA: 2015, 12). As megatendências em ciência e tecnologia serão marcadas pela economia da inovação, avanço científico e tecnológico transformando as sociedades movidas por automação, robótica, nano e biotecnologias, sendo certo que as tecnologias da informação e comunicação modificarão, substancialmente, além do que já está, as relações humanas. (2015: 13)

Por outro lado, ilustram que a moral, dominada pela razão técnica é a bússola que norteia as decisões. No entanto, os caminhos escolhidos pela razão através do instrumental da técnica, estão a anos-luz de preencher o vazio do espírito e aproximar o homem de seu Criador.

GALIMBERTI mergulhando em Prometeu Acorrentado, de Ésquilo, castigado por ter instruído os homens a apropriação da técnica e, portanto, do pensamento racional, aponta que a técnica é a razão que calcula e que aprisiona o homem, pois, “com a técnica, o homem se emancipa da divindade, porque obtem por si aquilo que, antes, era obrigado a implorar de deus". (2006: 270)

A razão é a responsável pelo esvaziamento do espírito e a deformação da alma. A deformação da alma é bem compreendida por AQUINO (2014: 108). É a protagonista no cenário da existência humana em convencer o homem de que, para a existência, basta corpo e alma; o Ente é dispensável, pois abandonou a sua criação para viver só. A razão avoca a condição de conduzir o homem em segurança, com a garantia de lhe proporcionar todos os avanços necessários para o preenchimento do vazio do espírito, dispensando-o de maiores reflexões que não sejam as individuais e as de independência do Criador, sobretudo, da obstinação existencial de acabar com tudo o que foi criado pelo Ente, pois, é um ser ressentido.

Esse ressentimento é muito bem fotografado por PONDÉ, ao considerar que a humanidade está excessivamente individualista e, sobretudo, narcisista. (2014)

Diante disso, a razão é a grande vilã da história. Ela é capaz, habilmente, de negar a gênese. Ela é a fera a ser domada. É nela que deve ser despejada a força neutralizante da vontade da alma preencher o espírito e ser excelente à imagem do Ente; da paixão e amor incondicional de sentir-se pleno e completo no Criador; e do espírito acender, novamente, o sentido da vida. É ela 
a responsável pelos horrores e deformações na moral, sujeitando a vontade e as emoções à mesma irracionalidade. É nela que depositado está todo o dilema.

Assim é que a moral deformada age, e sempre agiu, fortemente, sobre a sociedade, a economia, a política e a religião. Claro! São as vias pelas quais o homem se realiza no mundo. Esse é o seu universo de conformação natural! O Direito, como técnica desenvolvida pela razão dessa alma deformada, sempre foi servo fiel e, ainda presta exímio serviço em conformar a realidade a partir dessa deformidade. Qualquer tentativa de retorno é rechaçada pela razão.

Por isso, o Direito, como assistente imediato, sofre com os critérios de Justiça. O Direito está alojado na técnica da razão dessa moral sem prumo, e a Justiça reside no espírito, limpa e cristalina, sabedora da medida do prumo. Enquanto o homem não conformar a sua moral ao espírito, reencontrar o Ser com o Ente, certamente, os desequilíbrios históricos se perpetuarão até que seja exposta, de uma vez por todas, a nudez da sua moral e, com suas vergonhas a mostras, o homem possa retornar, em tempo de redimir-se, histórica e cientificamente.

GALIMBERTI, por outra abordagem, sustenta que, se houver uma ampliação psíquica do homem a ponto de conseguir dominar a razão técnica, é hábil para evitar que ocorra o absoluto técnico e a técnica aconteça sem que o homem a saiba e, de condição essencial, promova sua extinção. (2014: 828-829)

Nesse momento da pesquisa, basta deslocar a moral social e religiosa jazida no esquecimento histórico para o locus da economia, de forma nua, limpa e cristalina para que seja possível ao homem encontrar algum limite e equilíbrio no enfrentamento das questões jurídicas atinentes às nanotecnologias e, com isso, deixando a hipocrisia de lado, alcançar, limites às irracionalidades que, por ventura, tenha inclinação. A ciência, se socorrendo dos diálogos interdisciplinares e dos dados, talvez, ainda sirva para isso.

\section{0 pretexto da moral ortodoxa do capitalismo e o contexto para a moral radical desse início de século.}

Por uma questão de recorte metodológico, o marco histórico epistemológico à análise do objeto é o do Pós Segunda Guerra Mundial e as alterações significativas que houve nas sociedades espalhadas ao redor do globo, sendo a mais marcante, a pseudo decadência do capitalismo como sistema econômico dos povos da Europa Ocidental e América, diante do resultado catastrófico para as gentes e governos. 
A partir da Segunda Guerra, o capitalismo, por alguns, foi repensado, por outros, reforçado. Pelos países do chamado "Terceiro Mundo", eclodiu a luta pela emancipação política e, como consequência, a independência econômica.

Os quinze anos que se seguiram logo após o término da guerra foram de grandes acomodações internas nos países, em especial, os hegemônicos, europeus e Estados Unidos. Na maioria dos países europeus, os partidos socialistas, social-democratas e comunistas tornaram-se mais conservadores e retomaram as estruturas básicas da sociedade e da economia, defendendo a melhoria de vida dos trabalhadores. Já, nos Estados Unidos, o sistema foi retomado com agressividade, acentuando políticas violentas de combate ao comunismo, Guerra Fria e expansão da repressão social, política e intelectual, cujos resultados foram a quase destruição dos movimentos radicais e socialistas nas organizações sindicais e nas universidades. (HUNT: 2005, 472).

Demais disso, a guerra fria tinha como mote capitalistas versus comunistas e, portanto, inevitável. A maioria das pessoas se convenceram desse discurso ideológico e, com isso, acreditaram que o capitalismo, a bem da verdade, deveria avançar, pois era a única forma de eliminar a pobreza, as diferenças de classes, o imperialismo e a instabilidade econômica (HUNT: 2005, 472). Mas os resultados foram completamente adversos e os Estados Unidos soergueram-se como a grande potência bélica e econômica mundial, expandindo-se como imperialista.

Nas universidades, onde eram tratadas as ciências econômicas, também, a divisão foi sentida. As escolas austríacas e de Chicago foram tidas como extremistas, predominando as liberais de elite, pois, exerciam as críticas ao sistema.

Os países capitalistas foram fortemente abalados entre 1960 e 1970, devido ao aumento das crises social, econômica, política e ideológica internas, representadas pelo alto índice de desemprego, inflação crônica, crises monetárias, inclusive, nos Estados Unidos, com movimentos pelos direitos civis, revoltas nos guetos urbanos, movimentos contra a guerra, descoberta de escândalos de fraudes no governo. Com isso, foi destruída "a convicção de muitos de que os governos capitalistas serviam ao povo de forma neutra, benevolente e democrática, interessados apenas em maximizar o bem-estar da população e promover a paz, a harmonia e a fraternidade em todo o mundo". (HUNT: 2005, 473) Discurso esse ideologizado pela ciência econômica ortodoxa (hiperracionalidade lucrativa) de visão utilitarista (o fetiche do consumo).

Nesse cenário de sentimento de fracasso, recobraram forças as críticas ao capitalismo de Marx e Veblen, as quais eram estudadas nas escolas de Chicago e da Áustria. Com isso, surge a 
escola da economia política crítica (radical), 1960, que incluía nas análises dos preços e dos lucros, a teoria do valor trabalho ${ }^{3}$.

Explica HUNT que uma das diferenças mais marcantes entre a ciência econômica ortodoxa e a radical reside, justamente, no fato de que, a primeira pensa que o homem econômico, racional e maximizador, explica todo o comportamento humano, enquanto a segunda, entende que, a economia deve ser estudada a partir dos aspectos econômicos, psicológicos, sociológicos e políticos da sociedade, pois, tudo está inter-relacionado. "Nenhum aspecto da sociedade pode ser adequadamente apreendido ou entendido isoladamente de seu lugar na totalidade orgânica de toda a sociedade". (2005: 482)

Ao longo da história, desde as primeiras conformações sociais econômicas, o utilitarismo econômico, enquanto ideologia do capitalismo ortodoxo, predominou como razão de decidir; estabeleceu a estrutura de classes, se apoiou no monopólio dos capitalistas sobre a propriedade dos meios de produção, que resultou em uma extrema desigualdade na distribuição de renda, capaz de gerar instabilidade e estagnação; propiciou ambiente para a irracionalidade e o caos que sempre caracterizam seu funcionamento, mitigados pelas intervenções governamentais ${ }^{4}$ de contenção.

E mais. O capitalismo avançou exponencialmente pelos territórios dos países do "Terceiro Mundo", hoje, identificados como "em desenvolvimento", para se livrar dessa irracionalidade e do caos, que são compreendidos pela absorção dos excedentes, da mais-valia, do excesso de produção. Esse fato é marcado pelo imperialismo econômico dos Estados Unidos ${ }^{5}$ e a dominação desses países, dentre eles, cristalinamente, o Brasil.

Depreende-se, portanto, que a escola econômica clássica, de orientação utilitária nunca foi despretensiosa de valores, ausente de sentimentos, de observação empírica do comportamento do homem, individual e coletivamente. É a partir da compreensão desse homem, do

\footnotetext{
${ }^{3}$ A teoria do valor trabalho representa uma medida invariável de valor em qualquer sistema capitalista, mas, rejeitada pelos economistas ortodoxos, pois, não está na base do lucro nem do excedente, da mais-valia. As análises de Marx sobre a natureza e estrutura de classes do capitalismo e a natureza e as origens do lucro exigem os conceitos de valor e de mais-valia.

4 "Dada a substancial influência dos capitalistas nos governos, o governo gasta e, portanto, absorve o excedente de maneiras que promovem as desigualdades de riqueza e de renda vigentes, ou pelo menos não interferem nelas". (HUNT: 2005, 486)

5 "Os EUA instalam e mantêm (econômica e militarmente) em numerosos países do Terceiro Mundo governos impopulares, corruptos e brutais; esses governos representam os interesses de reduzidas elites locais e de grandes empresas multinacionais; esses governos adotam políticas que frequentemente pioram uma já obscena desigualdade na distribuição da riqueza e da renda vigente nesses países; eles mantêm seu controle impopular e repressivo pelo uso amplo e sistemático do terror, da tortura e do assassinato contra qualquer cidadão que seja suspeito de críticas do governo. O governo dos EUA auxilia direta e indiretamente e apoia (e até ocasionalmente dirige e supervisiona) esses procedimentos, sempre em nome do combate ao 'comunismo' e da defesa da 'democracia'. (HUNT: 2005, 488)
} 
comportamento social, que a doutrina econômica foi elaborada para a maximização lucrativa. Foi feita uma escolha histórica racional da metodologia econômica. Nesse sentido, HUNT menciona que "a maioria dos economistas clássicos e todos os neoclássicos embasam sua teoria econômica numa concepção utilitária, hedonista, da psicologia e da ética humanas”. (2005: 489)

O utilitarismo tem sua defesa intelectual para conformar o sistema social sob dois argumentos: i) os sentimentos, as emoções, ideias, padrões de comportamento e desejos são tidos como metafisicamente dados, por isso, não são levados em conta pela administração financeira e econômica; ii) os desejos humanos são considerados independentes das interações sociais e a satisfação deles se dá pela via do consumo de mercadorias; o bem-estar humano depende da satisfação desses desejos, individualmente.

Já a escola econômica radical tem em sua defesa intelectual que: i) os desejos humanos são determinados, em boa parte, socialmente, e a satisfação deles pode ou não aumentar o bemestar humano; ii) que a produção é um fenômeno social em que nenhuma pessoa pode ser responsabilizada pelo todo produzido; iii) que a destinação dos produtos ao consumo é determinada socialmente, podendo ser benéfica ou prejudicial ao bem-estar humano, assim, definidos pela própria coletividade, que se apropria das regras de mercado.

Constata-se que ambas as escolas estão a considerar o homem e o atendimento de suas necessidades, individuais e sociais, sobretudo, depreende-se que tipo de homem pretendem atender: a ortodoxa, preocupada em satisfazer o homem pela metade (alma) porque com isso consegue maximizar lucros, entendendo que esse ser é esvaziado de sentido; a radical, preocupada em atender o homem na sua plenitude (alma + espírito), entendendo que esse ser pleno não se preenche com mercadorias, mas com o sentido de sua existência.

Trata-se de um paradoxo recente para a economia, mas antigo para as ciências filosóficas e sociais, podendo representar a possibilidade de rompimento e emancipação, a exemplo do que menciona HUNT: "os seres humanos sempre funcionam, pensam e escrevem com base em, dentre outras coisas, sentimentos, preceitos e conceitos morais". (2005: 490)

Assim, sob a análise desse dilema, as necessidades humanas universais inatas são separadas das individuais conscientes, as quais são conformadas pelo processo social a que o indivíduo é protagonista, entretanto, a socialização pode condicionar padrões de comportamento que torne a necessidade universal inata como individual e essa inversão seja o padrão de 
normalidade, esvaziando a individualidade que provoca ansiedade neurótica ${ }^{6}$ (sentimentos de pequenez, insignificância e desamparo) (HUNT: 2005,490). Esse é o perfil das gentes que estão sob o império do sistema capitalista: enfermidade crônica na alma, cuja expressão da razão é distorcida da realidade existencial da humanidade.

É possível com que está sendo visto até aqui, depositar nas grades desse sistema ortodoxo, a responsabilidade pelos fenômenos identificados como o individualismo exacerbado, a mitigação das soberanias políticas e econômicas dos países em desenvolvimento, a perda de identidade cultural, o desequilíbrio na exploração da natureza, as mudanças climáticas, a amputação da emancipação política dos povos, a degradação sexual, o apelo à sensualidade, a massificação do consumo, o aumento da criminalidade, da miséria, a concentração de riquezas globais; toda expressão humana deformada, a partir de si mesma.

Para o outro lado do paradigma HUNT conclui seu trabalho crítico sustentando que o conceito de bom para os seres humanos e de seu bem-estar, consiste nas estruturas da vida social e que cada um seja considerado como fim em si mesmo. Assim, é possível identificar um desejo universal de que cada pessoa alcance o máximo de sua auto - realização (biológica, emocional, intelectual, criativa e estética) e uma preocupação unificada consigo mesmo que reflete, diretamente, no outro. (2005: 492)

Por tal contextualização sumária e rasa, é possível perceber que o sistema capitalista deu certo e uma produção infindável de tentáculos sistêmicos e de produtos ao consumo, não é capaz de saciar o homem que reclama mais satisfação à sua insatisfação, desapercebendo-se que é existencial. Com isso, todo o sistema global caótico está -falsamente - justificado e é tido como padrão de normalidade do qual derivam todas as implicações dos sistemas que são pensados, a partir de então.

Mas isso não ocorreu com um estalo de dedos. A escolha foi realizada no século XVI, com a derrocada do feudalismo e o avanço do mercantilismo, momento de acumulação primitiva. Então, o início do século XXI, pode ser marcado pela apropriação do direito de decidir novamente por qual caminho social e econômico seguir; o capitalismo radical é uma possibilidade para a pesquisa. Com isso, também, significa dizer, que o homem precisa escolher retornar à plenitude de seu espírito para recuperar a chama perdida e, assim, curar a alma e retomar o sentido de sua existência mediante a apropriação social.

\footnotetext{
6 “Esses sentimentos não seriam neuróticos se a pessoa percebesse que eles decorrem da negação social da essência real dessa pessoa e que uma sociedade que nega aos seres humanos sua humanidade pode ser de fato mudada por uma ação humana coletiva”. (HUNT: 2005,490)
} 
Muito embora, pareça uma escolha impossível de romper, porque o sistema arraigou suas verdades como absolutas, muitos multiplicadores são encontrados resistindo ao que aí está e o Direito, mais uma vez, é o servo fiel da razão que se permite ser usado como ferramenta da moral que, por sua vez, ostenta a política e a economia como pano de fundo e a justiça como moldura. É, de fato, por onde tudo o que é pensado é materializado, na prática. É hábil para sair da compreensão e se efetivar no chão da sociedade.

Nessa seara de reflexões, para a juridicização dos fatos sociais, políticos e econômicos que permeiam as nanotecnologias, imprescindível que o Direito, de forma limpa e honesta, mas, sobretudo, parcial, ao lado da moral excelente e do capitalismo radical, dê contribuição estruturante e reveladora de uma nova ordem social: o homem como fim de todo desenvolvimento. Esse é o princípio estruturante da moral social e econômica que o Direito deverá pensar. Sim, deverá servir à moral social e econômica pois, ambas estão fundidas.

O Direito a serviço da moral social causa prejuízo econômico à sociedade; a serviço da economia, como já vimos, causa problema social. Então, a conclusão, partindo de uma moral excelente, é estabelecer como razão de pensar, a moral social fundida com a econômica e, depois, a política, porque a economia e a política, também estão fundidas entre si. Assim como ENGELMANN menciona, os princípios são a base do pensar (2001: 88) e a razão de decidir; uma moral excelente para um bom início de juridicização é escolher o princípio pelo qual todo pensamento jurídico irá perpassar.

\section{O diálogo entre Alexy e Posner a respeito da eficiência da moral socioeconômica e jurídica para o enfrentamento do Direito das Nanotecnologias}

Os princípios são a razão de pensar.

É no campo dos princípios que reside a moral estruturante, fundamental. A lei, por sua vez, é a expressão da razão prática, que se realiza a partir da técnica. A justiça, de outra borda, fica nas impressões do espírito - muito distante! - e, portanto, não tem parte com a moral, muito menos com a lei. O Direito, em toda sua complexidade estrutural de fontes, é o administrador técnico desse cenário repartido da conformidade humana, que se reflete na conjuntura social, locus do agir do Direito, como consequência, lugar histórico de revolver-se com os ideais da Justiça. Impossível, pois não tem parte com ela, ela está no Ente e o homem e sua moral estão alojados no Ser.

Entretanto, a proposta, a partir daqui, é a de estabelecer, por tudo o que foi construído, até agora, que os princípios fundantes do Direito das Nanotecnologias devem ter como pedra de 
esquina, as bases do capitalismo radical (sic) para promover como resultado, a retomada da moral excelente e, via reflexa, alçar o Direito a Justiça.

Como laboratório, o capitalismo radical deverá se infiltrar nos princípios estruturantes do Direito das Nanotecnologias, a fim de que as fontes possam ser elaboradas a partir dessa fusão entre economia e Direito e alcançar a eficiência social.

Para ENGELMANN que entende que os princípios são a razão de pensar a sociedade, o Direito e a Justiça, salienta que, no perfil, eles têm caráter polêmico e polissêmico e que "pode-se dizer que os mesmos representam as linhas gerais do Direito, responsáveis pela formação do sistema jurídico". (2001, 95)

O norte dos princípios que orienta, ou deveriam orientar o Direito, no Brasil, estão sistematicamente catalogados na Constituição da República, dos quais, todos os demais, a partir dela, estão ou deveriam estar, a ela, sujeitos, pois, é nela que estão contidas as razões de pensar o país.

E mais. É possível diagnosticar um princípio nacional muito maior, de prospecção interna e externa, que é o contido na bandeira institucional do país: ordem e progresso. Essas duas palavras significam que o país está, claramente, assentado em dois princípios estruturantes: social e econômico. Essa compreensão é possível tendo em vista o local histórico de suas afirmações e o andar da história, até aqui. Portanto, já, em 1988, o Brasil assumia a posição de alavancar todo o processo social a partir da economia, possível de verificar, também, da leitura atenta do preâmbulo e do artigo $1^{\circ}$, os quais convalidam a intenção flamular.

Então, não há mais como discutir essas ideias no campo das ideologias políticas, porque é fato escolhido pela alma da nação. A democracia já está consolidada no Brasil, agora, é o momento da eficiência. Estamos, na régua histórica, no momento de proporcionar eficiência a esses princípios estruturantes escolhidos por nós. Então, não há nenhuma eficiência em retroceder. Não há mais tempo para voltar a ser um país criança. Havia outras escolhas, outros caminhos, mas a nação escolheu este: uma sociedade econômica por base de sua existência e conformação social, sendo esse seu padrão de moralidade.

Portanto, todos os princípios, quando usados, que não estejam afetos a essa fusão são mal interpretados porque, muito embora, a nação tenha escolhido esse caminho em 1988, o chão social não compreendeu o que foi feito, ou como isso funciona, porque não houve sua emancipação necessária para tal, e diante da ineficiência da administração nacional por questões inúmeras, desde então, reclama outro caminho, mediante ideologias que, nesse momento de globalização e tecnologia, não funcionam mais, a não ser, para mergulhar o país no caos. 
Contudo, se nesse momento forem adotadas como regras de todo o sistema social, jurídico, político e econômico a compreensão do princípio maior que é o da fusão social e econômica, e essa razão de pensar for capaz de refletir no dia-a-dia do país, certamente se, e somente se, de forma adequada, haverá uma harmonia capaz de instaurar a eficiência em todos os setores.

E, na esfera jurídica não é diferente, senão, essencial, pois faz parte de uma das esferas de poder político do país, que também está debaixo dessa moralidade, e que já vem dando amostras consideráveis de tudo o que se está a dizer, a partir de decisões judiciais em todas as esferas de reclamação, a moral econômica para atingir o chão social tem sido a razão de pensar o Direito e isso tem passado pelo filtro dos princípios.

Esse discurso tem amparo.

ENGELMANN, de forma coerente com a proposta da pesquisa, propõe classificar os princípios assim: i) princípios fundamentais, como aqueles esculpidos na Constituição da República e demais proposições jurídicas; ii) princípios fundamentais secundários que revelam as orientações do pensamento, residindo aqui, a moral fundante considerada na construção do pensamento como extrajurídica ${ }^{7}$; iii) princípios de sistematização, aqueles capazes de delimitar e conformar o sistema de normas e regras jurídicas; iv) princípios hermenêuticos para a aplicação do direito e que devem orientar o pensamento no momento de uso das normas jurídicas. (2001:103)

É nessa categoria dos princípios fundamentais chamados de secundários, onde está alojada a moral extrajurídica, que os doutrinadores dogmáticos esperneiam em favor ideológico da sistemática positiva e mantença da tradição técnica do Direito, negando-lhe espaço de interferência sob a pecha da bandeira da insegurança jurídica. Quando, a bem da verdade, seria uma emancipação do Direito admitir a interferência da moral no seu quadro anêmico de fontes. É possível perceber que isso se dá em decorrência da asfixia sintomática causada pela razão técnica que não admite, e sequer permite, que o homem retorne às impressões do espírito e da Justiça, cujo caminho é a moral sã.

Mas, é, justamente nesse ponto que ENGELMANN os considera possíveis de serem incorporados ao sistema jurídico como função normativa ou mediante a atividade judicial, capaz de fechar a completude de regras, a partir da moral estruturante. A isso o Professor chama de "norma de clausura do sistema de liberdades", que é compreendido como sendo "a liberdade

\footnotetext{
${ }^{7} \mathrm{Na}$ construção do pensamento das categorias dos princípios, Engelmann parafraseia Aulis Aarnio e a leitura que faz de uma das categorias é a dos princípios extra - sistêmicos, que são aqueles de conotação extrajurídica e de caráter moral que devem ser levados em considerados no universo jurídico e têm função de orientar o pensamento jurídico e os seus significados ideológicos. (ENGELMANN: 2001,98)
} 
jurídica como a garantia institucional da liberdade natural, de modo que qualquer limitação que possa ser lançada sobre esta, caracteriza-se como uma restrição à liberdade jurídica e, desta forma, aos direitos fundamentais". (2001:102)

Bingo! Uma vez que os princípios fundamentais extrajurídicos sejam a razão de pensar o Direito, qualquer regra jurídica que não contenha essa soma como resultado, deverá ser remanejada para que essa eficiência seja promovida no caso concreto. Essa é a posição ótima almejada pelo Estado Democrático de Direito e onde residem as crises jurídicas que não são identificadas pelos operadores de plantão.

E é nessa conta de soma 10 na eficiência, que os pensamentos de Alexy e de Posner auxiliam nessa reorganização jurídica de pensar o Direito das Nanotecnologias. Alexy estuda as regras jurídicas fundamentais para alcançar a eficiência social, que têm como pano de fundo, a eficiência econômica; e Posner, a partir da eficiência econômica, mostra como alcançar a eficiência social. Por isso, vale travar um diálogo sobre a eficiência a partir da fusão socioeconômica que o Direito brasiliense deve aparelhar e condiga com a pretensão maior da Constituição da República.

Além disso, Alexy observa o sistema jurídico a partir da estrutura do seu país, que regra a sociedade pela codificação de normas. Já, Posner, observa o sistema jurídico a partir da estrutura da sociedade pelo common law, a denotar a riqueza da contribuição do diálogo.

Na proposta de ALEXY, os princípios dialogam de forma harmônica e exponencial com as regras jurídicas para fechar a completude normativa. Princípios e regras fazem parte da categoria-gênero norma. Os princípios, para ele, otimizam, da melhor maneira possível, o sistema de normas; proporciona qualidade ao Direito, são "mandatos de otimização"8.

Ora, otimizar significa proporcionar eficiência na aplicação do Direito, a partir dos princípios. Por sua vez, otimização está relacionada a sinônimos como pró-atividade, movimento adiante, avanços, saltos qualitativos, alavancagem de qualidade, signos estes de conotação de resultados positivos, maximização de riquezas sociais ${ }^{9}$. O próprio ALEXY se socorre de operações lógicas da matemática para conferir eficiência à aplicação do peso concreto dos princípios de sua teoria, como se depreende do Posfácio escrito em 2002, de sua obra de 1986, almejando, com isso, critérios. (2015: 575-627)

\footnotetext{
${ }^{8}$ Engelmann explica que os mandatos de otimização se caracterizam pelo fato "de que podem ser cumpridos em diferente grau e que a medida de seu cumprimento não depende apenas das condições reais, mas também das jurídicas”. (2001: 108)

${ }^{9} \mathrm{O}$ conceito de maximização de riquezas difere, em muito, de maximização de lucros. Conforme Posner, trata-se da doutrina jurídica-econômica que analisa a relação custo-benefício para orientação das decisões judiciais. Não se trata de análise financeira, envolvendo perdas e ganhos pecuniários, mas, sim, sobretudo, a eficiência das normas que inclui ganhos ou perdas não pecuniárias.
} 
Assim, é possível fazer a leitura da teoria de Alexy de que, se o Direito positivo não é eficiente para atender às demandas sociais, dada a impossibilidade de subsunção universal, os princípios como razão de pensar e orientar o Direito devem ser vivificados como critérios para promover a máxima eficiência na solução das pendências jurídicas, estando ou não previstos na Constituição Federal, positivados ou não. E, se os princípios fundamentais contêm a moral socioeconômica, maximizar o Direito significa conformar essa realidade.

Ele mesmo menciona que "uma constituição é uma ordem-fundamento em sentido qualitativo e quantitativo substancial se por meio delas são decididas questões que sejam fundamentais para a comunidade". E prossegue: “de acordo com a teoria dos princípios, uma boa constituição deve conciliar as duas coisas. Ela tem que ser tanto uma ordem-fundamento quanto uma ordem-moldura". (ALEXY: 2015, 584)

Ao entender a teoria de Alexy, ENGELMANN diz que "tomando-se em conta esses argumentos (os acima expostos), cabe observar que não são os princípios que apresentam a ‘dimensão de peso', mas as razões e os fins aos quais eles fazem referência”. (2001: 109)

POSNER, por sua vez, mas por outro caminho, salienta que a teoria da análise econômica do direito se predispõe a maximizar riquezas sociais e, portanto, tornar o direito eficiente. Para isso, não é possível sói acontecer sem a economia servir de baliza para o direito - tudo gira em torno do dinheiro! -. Com isso, não se está a ideologizar a pesquisa - de direita ou de esquerda (sic) - mas, que os poderes da República precisam ser eficientes, já que são democráticos. Diz ele:

A novidade do movimento 'direito e economia' está simplesmente em insistir que os
juízes, ao tomar decisões, exerçam sua ampla discricionariedade de modo que se
produzam resultados eficientes, entendidos no sentido de resultados que evitem o
desperdício social. [...] E continua: a análise econômica do direito não se aplica somente
às áreas de direito privado, como o direito dos contratos e a responsabilidade civil
extracontratual. Pode-se aplicar, também, a muitas áreas do direito público... (2010: XV)

Muito embora, Posner administre muito melhor do que Alexy a discricionariedade judicial - para os positivistas é o problema e para os do sistema da common law é a solução - é possível denotar que ambos, cada um em seu sistema jurídico, pretendem dar caminhos que permitam ao direito ser eficiente, chegar até o chão social, e agregar resultados positivos e satisfatórios. Mas, também, denota-se que, ambas as teorias foram elaboradas a partir do contexto da moralidade social, política e econômica.

Alexy, jurista alemão, cuja Constituição de Weimar é um arcabouço de intenções em recuperar os efeitos negativos da moral do país por causa da Segunda Guerra Mundial; recheada de padrões de distribuição social igualitária por um Estado paternalista e cheio de bondades. Ao 
Estado, resta a condução do povo. Do outro lado, Posner, americano, de Constituição Liberal e eminentemente econômica; recheada de padrões igualitários de responsabilidades individuais que conformam um todo produtivo; cada cidadão é emancipado à condição de corresponsável com o crescimento do país, que se dá pela via do trabalho duro; basta ler o discurso de Benjamin Franklin em WEBER sobre A ética protestante e o espírito do capitalismo (2004: 42-44). Ao Estado resta a condução política.

Essa moral que está por detrás das teorias não escapa ao Brasil que, tem a sua formada, num primeiro momento, pela colonização de exploração e, posteriormente, pela política do café. De lá para cá, a Constituição Federal de 1988, pretende emancipar o país e reescrever essa história, mas essa questão depende da moral que se riscou no diploma político de 1988.

POSNER, não avesso ao panorama geral brasiliense, diz em seu livro A Economia da Justiça, traduzido para a Língua Portuguesa, que a abordagem econômica e jurídica tem suas contribuições a dar para o Brasil: i) formação dos juízes; ii) o fato de o país estar em desenvolvimento. (2010: XVII)

E ainda, por cima de tudo, reconhece que os juristas brasileiros, muito preocupados com metodologias conservadoras, têm dificuldades no enfrentamento do direito como fator político, impedindo o avanço da discricionariedade judicial e a permeabilidade do processo judicial por outras disciplinas, a exemplo da economia. (2010: XVII)

Posner está do lado da escola do capitalismo radical porque verifica a anarquia moral que se concebe no mercado, locus das nanotecnologias que estão alojadas em um vácuo sócio jurídico.

Assim, a partir das duas teorias convergentes é possível construir algo jurídico nacional relevante para tratar o Direito das Nanotecnologias, levando-se em conta, conceitos de eficiência jurídica e econômica inseridas nos princípios, os quais não podem dispensar itens de moralidade excelente, que só a teoria da Análise Econômica do Direito pode incutir.

Para POSNER a teoria é sistêmica quando diz que "a estrutura econômica implícita no common law em diversos estudos das normas e instituições jurídicas, bem como análises dos procedimentos e das decisões judiciais” parte da análise econômica do direito (2010: 8).

Aqui, no Brasil, a teoria vem sendo aplicada em vários setores, mas, muito discretamente e com conotação de metodologia de resolução de conflitos. No caso das nanotecnologias, é deveras interessante que a teoria possa repousar em harmonia e cumprir o desiderato constitucional, como se verá.

A Análise Econômica do Direito pretende romper com a razão técnica do sistema ortodoxo de capitalismo. É através da racionalidade limitada que se alcança a eficiência jurídica e 
econômica e se maximiza as riquezas sociais. $\mathrm{O}$ valor agregado a ser computado está no bem-estar do indivíduo e sua auto - realização, o que difere, em muito, da massificação do consumo, sustentado pela economia clássica.

A teoria rompe com o sistema quando trava a batalha entre valor e preço ${ }^{10}$. Preço está ligado ao cálculo do custo; valor, à potencialização agregada, que vai muito além do preço, além do fetiche de consumo como bem-estar.

A partir da leitura pretenciosa do artigo 170, da Constituição Federal é possível identificar que o Constituinte de 1988, diferenciou ordem econômica e financeira. A economia é o todo social no mercado e a financeira, é o resultado do dinheiro circulado. E mais. Nomeia o capítulo como sendo o dos princípios gerais da atividade econômica, ou seja, a moral comportamental na praça econômica chamada de mercado.

Além disso, assim como as categorias presentes na teoria, o artigo 170, também, descreve categorias tal qual, hábeis à eficiência e a maximização de riqueza social pelo valor agregado. Então, a teoria já está prevista na Constituição Federal.

Olhando para a redação do dispositivo político, a livre iniciativa obterá lucro financeiro a partir da ciranda econômica que é gerida pelos princípios de moralidade que rompem com a hiperracionalidade lucrativa; segundo, os nove princípios econômicos mais o parágrafo único mostram o que a sociedade brasiliense entende o que deseja como valor agregado; terceiro, a inclusão no caput de dignidade, valor do trabalho e justiça social, fecham a compreensão da moral socioeconômica nacional.

GRAU tratando do aspecto em comento da Constituição Federal, diz que o país escolheu o sistema capitalista para desenvolver-se, e como modelo de operar esse sistema, rejeitou a economia liberal - a ortodoxa - e, optou pela intervenção do Estado na economia - o neoliberalismo. E que o faz a partir dos princípios que mostram toda a ideologia por detrás da textura harmônica dos princípios constitucionais. Prossegue para esclarecer as ambiguidades possíveis, dizendo que o país é Estado Democrático de Direito e não Estado de Direito social; com isso, que a busca pela realização do bem-estar cabe à sociedade e ao Estado. (2015: 304-307)

Uma vez entendida que a teoria já está no ordenamento, o modelo de intervenção como ferramenta de promoção da eficiência e da maximização pode ser alcançado pela chamada Tríplice Hélice nessa fase de estruturação para o desenvolvimento.

\footnotetext{
10 “Embora o conceito de valor seja inseparável do de mercado, valor não é o mesmo que preço. O preço de uma mercadoria é o valor desta para o consumidor marginal, e os consumidores intramarginais a valorizarão mais alto, no sentido de que estariam dispostos a pagar um preço mais alto por ela. (POSNER: 2010,73)
} 
E esse ferramental é um dos possíveis de eleição porque a teoria é aplicada em todos os setores da sociedade, como um sistema. GICO esclarece que para a aplicação da teoria é importante “empregar os variados ferramentais teóricos e empíricos econômicos e das ciências afins para expandir a compreensão e o alcance do direito e aperfeiçoar o desenvolvimento, a aplicação e a avaliação de normas jurídicas, principalmente com relação ás suas consequências”. (2012: 2-33)

A Hélice Tríplice (ETZKOWITZ: 2009) envolve de forma integrada, universidade, indústria e governos na promoção do desenvolvimento seguro, eficiente e maximizador, pois, tem na sua proposta teórica e prática elementos sociais (universidade), econômicos (indústria e Governo) e jurídico (instrumental de concretização e convergência dos interesses).

A universidade assume o papel de estimular a criação de empresas a partir do desenvolvimento científico inovador, introduzindo a capitalização do conhecimento. As empresas, por sua vez, desenvolvem treinamentos para níveis cada vez mais alto no compartilhamento dos ativos intelectuais por meio de contratos de joint venture. O governo, como capitalista público, interessado e interventor na economia, promove a integração desses contratos ao mesmo tempo em que mantem atuação regulatória, cumprindo seu mister Constitucional.

Todo o foco de desenvolvimento, nesse momento, sai da universidade, local onde se desenvolve avanço e segurança científica, o que é imprescindível nesse cenário de risco que as nanotecnologias já demonstram promover.

\section{CONCLUSÕES}

É a partir de uma inquietação sistêmica que a pesquisa partiu e as nanotecnologias, um de seus aspectos.

De um lado, a técnica do Direito insuficiente e ineficiente para atender às demandas que gravitam em torno das nanotecnologias, que coloca em risco a sociedade e favorece a exploração econômica na forma clássica, pois está inserido em aparente crise existencial pelos juristas de plantão.

De outro, a necessidade de recolocar as questões morais, políticas e econômicas dentro desse cenário jurídico para conseguir estruturar um Direito das Nanotecnologias que não postergue essa ineficiência e insuficiência. 
Então, foi a partir da investigação da moral econômica que o dilema foi resolvido, que permite avançar no tratamento jurídico dos riscos e avanços nanotecnológicos. Inclusive, possível estruturar um Direito das Nanotecnologias sem hipocrisia.

Para isso, revolver a história econômica, política e social foi necessária para desnudar a moral, que sempre foi econômica e esteve presente o tempo todo no Direito, tanto positivo, constatado estudando os princípios na teoria de Alexy, quanto no sistema do common law, na teoria da Análise Econômica do Direito, em Posner, colimando na análise no artigo 170, da Carta Política Nacional.

Para resolver a problemática, a partir dos dados e da revisão bibliográfica interdisciplinar, confirmou-se a hipótese de que a Análise Econômica do Direito é suficiente para estruturar o Direito das Nanotecnologias e, nesse modelo deve ser todo o pensamento jurídico perpassado por princípios ideológicos, de moral excelente e de valor agregado.

\section{REFERÊNCIAS}

ALEXY, Robert. Teoria dos Direitos Fundamentais. $2^{\circ}$ ed. $4^{\circ}$ tiragem. Malheiros. São Paulo, 2015.

AQUINO, Tomás. A criação, a conservação e o governo do mundo. Ecclesiae. São Paulo: 2014.

ARISTÓTELES. Os econômicos. Imprensa Nacional-Casa da Moeda. Lisboa, 2004.

DWORKIN, Ronald. Levando os Direitos s sério. Martins Fontes. São Paulo, 2014.

ENGELMAnN, Wilson. Crítica ao positivismo jurídico. Princípios, Regras e o Conceito de Direito. Sergio Antonio Fabris Editor. Porto Alegre, 2001.

ETZKOWITZ, Henry. Hélice Tríplice: universidade-indústria-governo: inovação em ação. EDIPUCRS. Porto Alegre, 2009.

GALIMBERTI, Humberto. Psiche e Techne.O homem na idade da técnica. Paulus. São Paulo, 2006. 
GICO JR., IVO. Introdução ao Direito e Economia. In TIMM, Luciano Benetti. (org) Direito e Economia no Brasil. Atlas. São Paulo, 2012.

GRAU, Eros Roberto. A ordem econômica na Constituição de 1988. $17^{\circ}$ ed. Malheiros. São Paulo, 2015.

HUNT, E. K. História do Pensamento Econômico. Uma perspectiva crítica. $2^{\circ}$ reimpressão. Campus. Rio de Janeiro, 2005.

IPEA. Megatendências Mundiais 2030. O que entidades e personalidades mundiais pensam sobre o futuro do mundo? Contribuição para um debate de longo prazo para o Brasil. Organizadora Elaine C. Marcial. Brasília, 2015. Disponível em www.ipea.gov.br acessado em 10/05/2016.

PONDÉ, Luiz Felipe. A era do ressentimento. Uma agenda para o contemporâneo. Leya. São Paulo, 2014.

POSNER, Richard. A economia da Justiça. Martins Fontes. São Paulo, 2010.

SCHELER, Max. Do Eterno no Homem. Vozes, Rio de Janeiro e Editora Universitária São Francisco, São Paulo, 2015.

WEBER, Max. A ética protestante e o "espírito" do capitalismo. Companhia das Letras. São Paulo, 2004.

ZANNI, Amedeo Orlandini. El "pensar" ético ante la nueva complejidad. Revista de Filosofia. Volume 34. $\mathrm{n}^{\circ}$ 102, set/dez. México, 2001.

ZYLBERSZTAJN, Décio; SZTAJN, Rachel. (org) Direito \& Economia. Análise Econômica do Direito e das Organizações. $2^{\circ}$ reimpressão. Campus. Rio de Janeiro, 2005. 